\title{
Diesel exhaust particles induce a Th2 phenotype in mouse naïve mononuclear cells in vitro
}

\author{
KEN-ICHIRO INOUE ${ }^{1}$, EIKO KOIKE ${ }^{2}$, AKIKO ENDOH $^{3}$, DAIGO SUMI $^{3}$, YOSHITO KUMAGAI $^{3}$, \\ KAZUICHI HAYAKAWA ${ }^{4}$, MASAKO KIYONO ${ }^{1}$, MICHITAKA TANAKA ${ }^{1}$ and HIROHISA TAKANO ${ }^{2}$ \\ ${ }^{1}$ Department of Public Health and Molecular Toxicology, School of Pharmacy, Kitasato University, Tokyo; \\ ${ }^{2}$ Environmental Health Sciences Division, National Institute for Environmental Studies, Ibaraki; \\ ${ }^{3}$ Graduate School of Comprehensive Human Sciences, University of Tsukuba, Ibaraki; \\ ${ }^{4}$ Faculty of Pharmaceutical Sciences, Kanazawa University, Ishikawa, Japan
}

Received May 20, 2010; Accepted July 15, 2010

DOI: $10.3892 / \mathrm{etm} .2010 .129$

\begin{abstract}
It has been shown that pulmonary exposure to diesel exhaust particles (DEP) exacerbates allergic manifestations (i.e., allergic asthma) in vivo. However, the underlying mechanisms remain enigmatic. Furthermore, DEP components responsible for the exacerbation remain unidentified. Hypothesizing that DEP induce a helper $\mathrm{T}$ (Th)2-biased condition in immune mononuclear cells even in the absence of an allergen, the present study elucidated the effects of DEP and their components on the characterization of primary splenocytes and $\mathrm{T}$ cells in vitro. ICR mouse-derived splenic mononuclear and $\mathrm{T}$ cells isolated from the splenocytes were co-cultured with organic chemicals in DEP extracted with dichloromethane (DEP-OC $0.5-50 \mu \mathrm{g} / \mathrm{ml}$ ), residual carbonaceous nuclei of DEP (washed DEP $0.5-50 \mu \mathrm{g} / \mathrm{ml}$ ) or 'whole' DEP (1-100 $\mu \mathrm{g} / \mathrm{ml})$; thereafter, interleukin (IL)-4 and IgE production by these cells and the surface expression of CD19, IL-4R, CD69 and the CD40 Ligand (L) were evaluated by means of ELISA and flow cytometry. DEP and their components increased IL-4 and total IgE levels in a concentration-dependent manner $24 \mathrm{~h}$ after culture, and the effects were greater with washed DEP than with DEP-OC. On the other hand, each DEP component increased the surface expression of CD19 on splenocytes and that of IL-4R, CD69 or CD40L on both splenocytes and isolated T cells; however, the impact was greater with DEP-OC. These results suggest that DEP cause naïve mononuclear cells, including $\mathrm{T}$ cells to enter a Th2-biased state and that each DEP component plays a differential role in the efficacy.
\end{abstract}

Correspondence to: Dr Ken-ichiro Inoue, Department of Public Health and Molecular Toxicology, School of Pharmacy, Kitasato University, 9-1 Shirokane 5-Chome, Minato-ku, Tokyo 108-8641, Japan

E-mail: inouek@pharm.kitasato-u.ac.jp

Key words: diesel exhaust particles, splenocyte, $\mathrm{T}$ cell, helper T2 milieu

\section{Introduction}

It is generally accepted that diesel exhaust particles (DEP), derived from diesel engine-powered automobiles and major constituents in atmospheric particulate matter, are associated with several allergic disorders, which perhaps can be referred to as adjuvanticity (1). We and others have experimentally demonstrated that pulmonary exposure to DEP aggravates allergic airway inflammation and amplifies the lung expression of helper $\mathrm{T}$ (Th)2 cytokines in vivo (2-5). However, detailed mechanisms underlying the exacerbating effects of DEP on the allergic pathology remain unclear, particularly when analyzed only in in vivo samples.

DEP reportedly affect/disrupt several cell populations such as epithelial cells $(6,7)$, endothelial cells (8), macrophages (9), eosinophils (10) and mast cells/basophils $(11,12)$, which play roles in the pathogenesis of allergic inflammation, mainly in vitro. Furthermore, we (13) and others (14) have shown that DEP activate dendritic cells, one of the pivotal cell types involved in adaptive immunity, leading to maladaptive immune responses in vitro. However, the cellular contribution of DEP-mediated exacerbation of allergy has not been fully clarified.

Peripheral lymphoid organs and their resident mononuclear cells, including lymphocytes, are key players in the pathogenesis of allergic pathology; thus, the effects of DEP on these compartments might generate much information regarding their adjuvant effects on allergy. Previous studies have shown that DEP and their components directly/indirectly activate $\mathrm{B}$ cells to produce IgE in vitro $(15,16)$, implicating $\mathrm{B} /$ plasma cells in the mechanism of the adjuvant effects of DEP. However, less has been studied regarding the impact of DEP on T cells, in particular, in the context of Th lymphocyte differentiation/activation.

Another important issue is the fact that DEP have carbonaceous nuclei, which absorb organic chemicals, including polycyclic aromatic hydrocarbons (17). Previous studies have demonstrated that organic chemicals extracted from DEP have adjuvant potential for the production of allergen-specific immunogloblins in vivo (18) and in vitro (15). We previously 
reported that extracted organic chemicals from DEP with benzene-ethanol (referred to as 'DEP-OC'), rather than residual carbonaceous nuclei of DEP after extraction (referred to as 'washed DEP'), predominantly intensified allergenrelated airway inflammation in mice, although 'whole' DEP (before extraction) exhibited much greater adjuvant effects than DEP-OC or washed DEP (19). Nonetheless, the distinct effect/role of DEP components in naïve immune cells in vitro has never been reported.

Therefore, the aim of the present study was i) to examine the effects of DEP on naïve splenic mononuclear cells and $\mathrm{T}$ cells isolated from splenocytes and ii) to compare the effects of organic chemical components (DEP-OC) and residual particles of DEP (washed DEP).

\section{Materials and methods}

Animals. Male ICR mice at 6 weeks of age and weighing 29-33 g (Japan Clea Co., Tokyo, Japan) were used in all experiments. They were fed a commercial diet (Japan Clea Co.) and given water ad libitum. Mice were housed in an animal facility maintained at $24-26^{\circ} \mathrm{C}$ with $55-75 \%$ humidity and a 12 -h light/ dark cycle. The studies adhered to the National Institutes of Health guidelines for the experimental use of animals. All animal studies were approved by the Institutional Review Board of the National Institute for Environmental Studies.

Preparation of DEP. A 4JB1-type, light-duty, four-cylinder, 2.74 L Isuzu diesel engine (Isuzu Automobile Co., Tokyo, Japan) under computer control was connected to a dynamometer (Meiden-sha, Tokyo, Japan). DEP were collected in the dilution tunnel (stainless steel tubing) of a diesel inhalation facility by scraping the inside surface of the tubing as previously described (20). The collected DEP were referred to as 'whole' DEP and stored at $-80^{\circ} \mathrm{C}$ until use. Whole DEP were suspended in phosphate-buffered saline (PBS; Sigma, St. Louis, MO, USA) at pH 7.4 containing $0.05 \%$ Tween-80 (Nakarai Tesque, Kyoto, Japan) and $0.25 \%$ dimethyl sulfoxide (DMSO) (Nakalai Tesque). The whole DEP suspension was sonicated for $3 \mathrm{~min}$ with an ultrasonic disrupter (UD-201; Tomy Seiko, Tokyo, Japan), as previously described $(21,22)$.

Preparation of DEP-OC and washed DEP. DEP were extracted with benzene-ethanol as previously described (19). Briefly, $10 \mathrm{~g}$ of DEP was suspended in $800 \mathrm{ml}$ of benzeneethanol $(3: 1, \mathrm{v} / \mathrm{v})$ and was ultrasonicated for $30 \mathrm{~min}$. The suspension was centrifuged at $600 \mathrm{x}$ g for $20 \mathrm{~min}$. The supernatants were transferred to another tube and then were filtered with a membrane filter (pore size $0.45 \mu \mathrm{m}$ ). This procedure was repeated twice. The residual (solid) particles of DEP were prepared as washed DEP. The benzene-ethanol solution was evaporated to dryness in a rotary evaporator and then a vacuum pump, and the residue was dissolved in 100\% DMSO and prepared as DEP-OC. They were also stored at $-80^{\circ} \mathrm{C}$ until use.

Splenocyte preparation and DEP exposure. Spleens were removed from the ICR mice and placed in a Petri dish with PBS. The spleens were pushed through a 200-mesh stainless steel sheet, and the resulting cells were suspended in PBS.
Cells were collected by centrifugation at $400 \mathrm{x} \mathrm{g}$ for $10 \mathrm{~min}$ at $20^{\circ} \mathrm{C}$. Thereafter, red blood cells were removed by incubating with hypotonic lysis buffer for $3 \mathrm{~min}$. Cells were washed twice with PBS and resuspended in R10 [Gibco RPMI-1640 medium (Invitrogen, Grand Island, NY, USA), supplemented with $10 \%$ heat-inactivated fetal bovine serum (FBS; MP Biomedicals Inc., Eschwege, Germany), $100 \mathrm{U} / \mathrm{ml}$ penicillin, $100 \mu \mathrm{g} / \mathrm{ml}$ streptomycin (Sigma) and $50 \mu \mathrm{M}$ 2-mercaptoethanol (Invitrogen)]. The number of viable cells was determined using the trypan blue dye exclusion method. Splenocytes $\left(1 \times 10^{6}\right)$ were cultured in $1 \mathrm{ml}$ of $\mathrm{R} 10$ containing DEP-OC $(0.5,5$ or $50 \mu \mathrm{g} / \mathrm{ml})$, washed DEP $(0.5,5$ or $50 \mu \mathrm{g} / \mathrm{ml})$, whole DEP $(1,10$ or $100 \mu \mathrm{g} / \mathrm{ml})$ or the control $(0.1 \%$ DMSO, $0.05 \%$ Tween-80) in 12 -well plates at $37^{\circ} \mathrm{C}$ in a $5 \% \mathrm{CO}_{2} / 95 \%$ air atmosphere. After a 24-h incubation, cells were analyzed for FACS, and the culture supernatants were collected and frozen for subsequent interleukin (IL)-4 and total IgE analyses. Since the organic fraction of DEP constitutes $\sim 50 \%$ of total particle mass $(16,23)$, we set the concentration of each component.

T-cell isolation and DEP exposure. T lymphocytes were isolated by passing splenocytes $\left(1 \times 10^{8}\right)$ over a nylon fiber column (Wako Pure Chemical Industries Ltd., Osaka, Japan) based on a T-cell purification method. This method utilizes the principle of nylon fiber's affinity to B cells; thus, T-cell preparation of sufficient purity and without severe damages was achieved through the preferential adsorption of B cells to the fiber in the column (24). The column was incubated for $45 \mathrm{~min}$ at $37^{\circ} \mathrm{C}$ in a $5 \% \mathrm{CO}_{2} / 95 \%$ air atmosphere; thereafter, it was washed with R10 and the fraction of non-adherent cells ( $\mathrm{T}$ cells) was collected. The T cells were then resuspended in R10. The DEP exposure protocol and examination points and parameters (except for IgE) in the experiments were the same as for the splenocytes.

ELISA for interleukin (IL)-4. ELISA for IL-4 (Amersham, Buckinghamshire, UK) was conducted according to the manufacturer's instructions. The secondary antibodies were conjugated to horseradish peroxidase. Values generated by subtracting readings obtained at $450 \mathrm{~nm}$ from those at $550 \mathrm{~nm}$ were converted to $\mathrm{pg} / \mathrm{ml}$ using values obtained from standard curves generated with the limits of detection at $5 \mathrm{pg} / \mathrm{ml}$.

Total IgE determination. Total IgE antibody level was measured by IgE-capture ELISA $(2,25)$. In brief, microplate wells were coated with a rat anti-mouse IgE monoclonal antibody (BD Biosciences Pharmingen, San Diego, CA, USA) and incubated overnight at $4^{\circ} \mathrm{C}$. After washing with PBS containing $0.05 \%$ Tween-20 (PBST; Nakalai Tesque), microplate wells were incubated with $1 \%$ BSA-PBS and $0.01 \%$ thimerosal at room temperature for $1 \mathrm{~h}$. After washing with PBS containing PBST, diluted samples were added to the microplate and incubated overnight at $4^{\circ} \mathrm{C}$. After washing with PBST, biotinylated rat anti-mouse $\mathrm{IgE}$ was added to each well and incubated for $1 \mathrm{~h}$ at room temperature with $\beta$-D-galactosidase-conjugated streptavidin (Zymed Laboratories, San Francisco, CA, USA). After the final washing, the wells were incubated with 4-methylumbelliferyl- $\beta$-galactoside (Sigma) as the enzyme substrate at $37^{\circ} \mathrm{C}$ for $2 \mathrm{~h}$. The enzyme reaction was stopped with $0.1 \mathrm{M}$ glycine- $\mathrm{NaOH}$ ( $\mathrm{pH}$ 10.3). The fluorescene intensity 


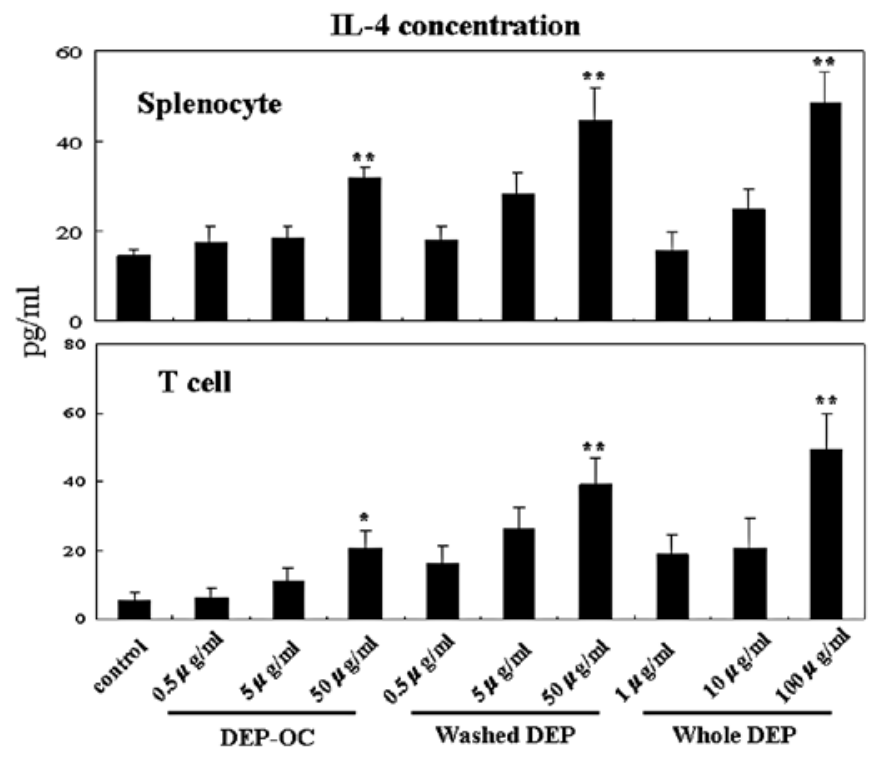

Figure 1. Effects of whole diesel exhaust particles (whole DEP) and their components [organic chemicals in DEP extracted with dicloromethane (DEP-OC)] or residual carbonaceous nuclei of DEP (washed DEP) on interleukin (IL)-4 production in splenocytes and $\mathrm{T}$ cells isolated from the splenocytes. The collection of splenocytes and T-cell isolation was conducted as described in Materials and methods. Splenocytes $\left(1 \times 10^{6}\right)$ or isolated T cells were cultured in $1 \mathrm{ml}$ of R10 containing DEP-OC $(0.5,5$ or $50 \mu \mathrm{g} / \mathrm{ml})$, washed DEP $(0.5,5$ or $50 \mu \mathrm{g} / \mathrm{ml})$, whole DEP $(1,10$ or $100 \mu \mathrm{g} / \mathrm{ml})$ or control (0.1\% DMSO, $0.05 \%$ Tween-80) in 12 -well plates at $37^{\circ} \mathrm{C}$ in a $5 \%$ $\mathrm{CO}_{2} / 95 \%$ air atmosphere. After a $24-\mathrm{h}$ incubation, the culture supernatants were collected, and IL-4 levels were measured by ELISA. Data are the mean \pm SEM of four individual cultures from four animals, representative of three independent experiments. ${ }^{*} \mathrm{P}<0.05,{ }^{* *} \mathrm{P}<0.01$ vs. medium.

was read using a microplate fluorescene reader (Fluoroskan Flow Laboratories, Costa Mesa, CA, USA). A450 readings of the samples were converted to nanograms per milliliter, using a standard curve generated with double dilutions of the mouse $\mathrm{IgE} \kappa$ isotype standard (BD Biosciences Pharmingen).

FACS analysis. For FACS analysis, the following monoclonal antibodies were used: IL-4R (CD124: mIL4R-M1, PE-conjugated), CD69 (H1. 2F3), CD40 Ligand (L) (CD154: gp39: MR1, PE-conjugated) and CD19 (FITC-conjugated) (all from BD Biosciences Pharmingen). Cells (1-3x10 $0^{5}$ were resuspended in $100 \mu \mathrm{l}$ PBS with $0.3 \% \mathrm{BSA}$ and $0.05 \%$ sodium azide (Wako Pure Chemical Industries Ltd.) and stained with antibodies at $1 \mu \mathrm{g}$ for $30 \mathrm{~min}$ on ice. After incubation, the cells were washed, and fluorescence was measured using a FACSCalibur (Becton Dickinson and Company, NJ, USA). For each sample, fluorescence data from 10,000 cells were collected, and positive cells were expressed as the percentage of total events.

Statistical analysis. Data are expressed as the mean \pm SEM of four animals from one experiment, representative of three experiments. Differences among groups were analyzed by ANOVA (Stat View version 4.0; Abacus Concepts, Inc., Berkeley, CA, USA). When significant differences were detected, post hoc comparisons within each group were evaluated with the Fisher's LSD test. Significance was assigned to P-values $<0.05$.
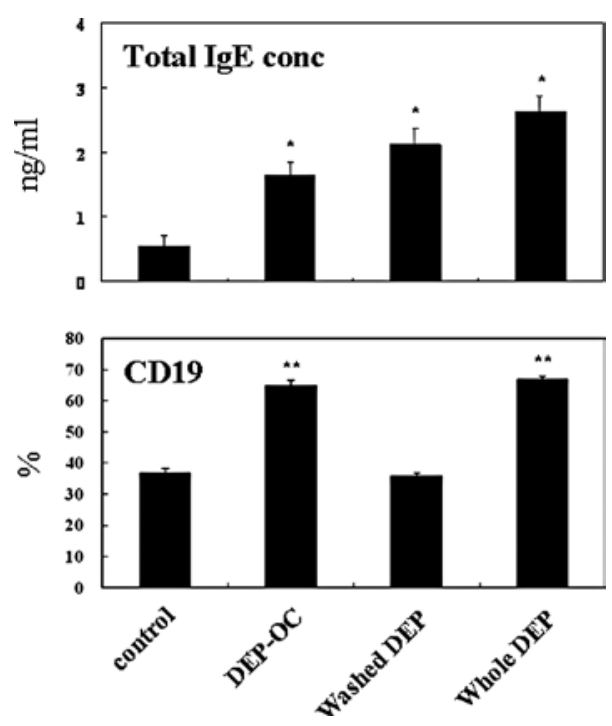

Figure 2. Effects of whole DEP and their components on total IgE production in splenocytes and CD19 expression on these cells. Splenocytes were resuspended to a cell density of $1 \times 10^{6} / \mathrm{ml}$ and $1 \mathrm{ml}$ was applied to each in 12-well plates. The splenocytes $\left(1 \times 10^{6}\right)$ were cultured in $1 \mathrm{ml}$ of $\mathrm{R} 10$ containing DEP-OC $(0.5,5$ or $50 \mu \mathrm{g} / \mathrm{ml})$, washed DEP $(0.5,5$ or $50 \mu \mathrm{g} / \mathrm{ml})$, whole DEP $(1,10$ or $100 \mu \mathrm{g} / \mathrm{ml})$ or control (0.1\% DMSO, $0.05 \%$ Tween-80) in 12 -well plates at $37^{\circ} \mathrm{C}$ in a $5 \% \mathrm{CO}_{2} / 95 \%$ air atmosphere. The total $\mathrm{IgE}$ level was measured by ELISA, as described in Materials and methods. In another experiment, the expression of CD19 on these cells was analyzed by flow cytometry. Data are the mean \pm SEM of four individual cultures from four animals, representative of three independent experiments. ${ }^{*} \mathrm{P}<0.01$ vs. medium.

\section{Results}

Effects of DEP on IL-4 production from naïve splenocytes and their T cells. To determine the effects of DEP exposure on naïve splenocytes and their $\mathrm{T}$ cells in the context of the $\mathrm{Th} 2$ milieu, we compared the protein levels of IL-4 in the supernatants $24 \mathrm{~h}$ after co-culture (Fig. 1). Exposure to whole DEP and their components elevated IL-4 levels in the supernatants from splenocytes and isolated $\mathrm{T}$ cells in a concentration-dependent manner as compared to IL-4 levels in the cells exposed to the control medium $[\mathrm{P}<0.01$ vs. whole DEP $(100 \mu \mathrm{g} / \mathrm{ml})$, DEP-OC $(50 \mu \mathrm{g} / \mathrm{ml})$ or washed DEP $(50 \mu \mathrm{g} / \mathrm{ml})$, except for T-cells exposed to DEP-OC $(50 \mu \mathrm{g} / \mathrm{ml})(\mathrm{P}<0.05)]$.

Effects of DEP on total IgE production from naïve splenocytes. To further determine whether DEP exposure biases these mononuclear cells towards a Th2 response, we compared protein levels of total $\mathrm{IgE}$ in the supernatants from the splenocytes $24 \mathrm{~h}$ after co-culture (Fig. 2). Whole DEP and their components increased the total IgE level in a concentrationdependent manner (data not shown). As compared to exposure to medium alone, exposure to whole DEP and their components at each maximal concentration elevated the value in the supernatants $(\mathrm{P}<0.01)$. However, in this context, whole DEP did not reveal synergistic effects of DEP-OC plus washed DEP, as observed in the previous in vivo study (19).

Effects of DEP on CD19 expression on naïve splenocytes and IL-4R, CD69 and CD40L expression on naïve splenocytes and their T cells. To determine the effects of exposure to DEP 


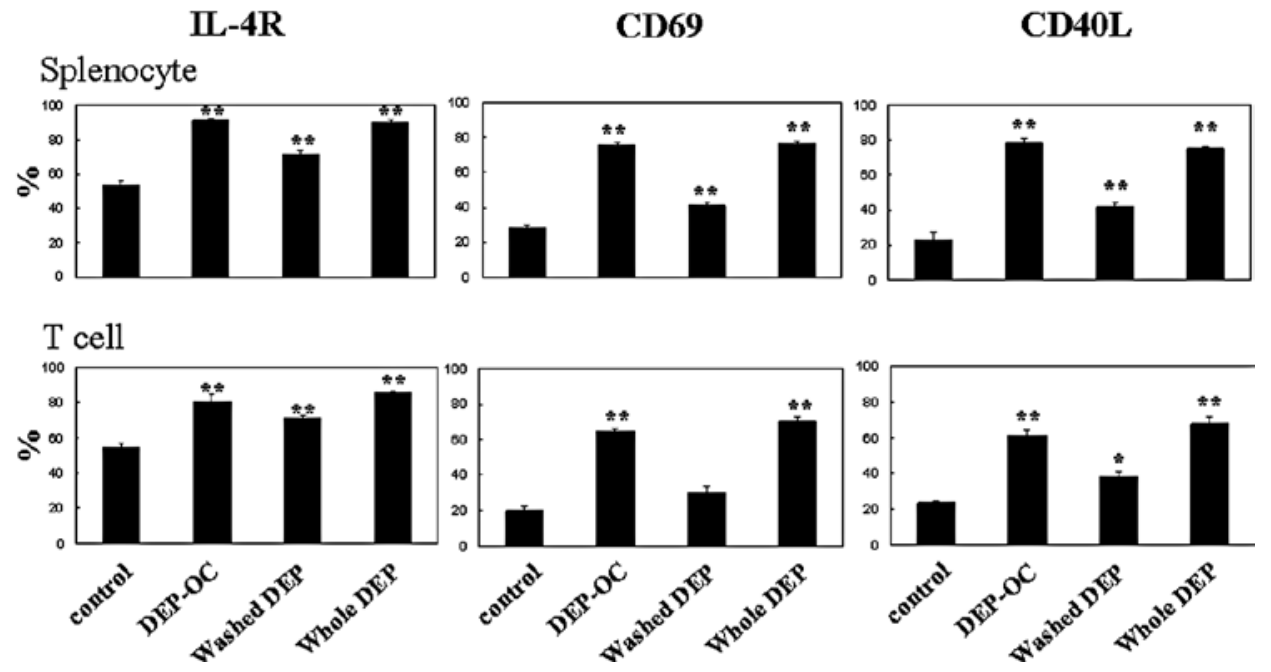

Figure 3. Effects of DEP and their components on the surface expression of IL-4R, CD69 or CD40 ligand (L) on splenocytes and isolated T cells. Splenocytes or isolated T cells $\left(1 \times 10^{6} / \mathrm{ml}\right)$ were exposed to DEP $(100 \mu \mathrm{g} / \mathrm{ml})$, DEP-OC $(50 \mu \mathrm{g} / \mathrm{ml})$, washed DEP $(50 \mu \mathrm{g} / \mathrm{ml})$ or medium (control) for $24 \mathrm{~h}$. Thereafter, the expression of IL-4R, CD69 or CD40L on the cells was analyzed by flow cytometry. Data are the mean \pm SEM of four individual cultures from four animals, representative of three independent experiments. ${ }^{*} \mathrm{P}<0.05,{ }^{* *} \mathrm{P}<0.01$ vs. control.

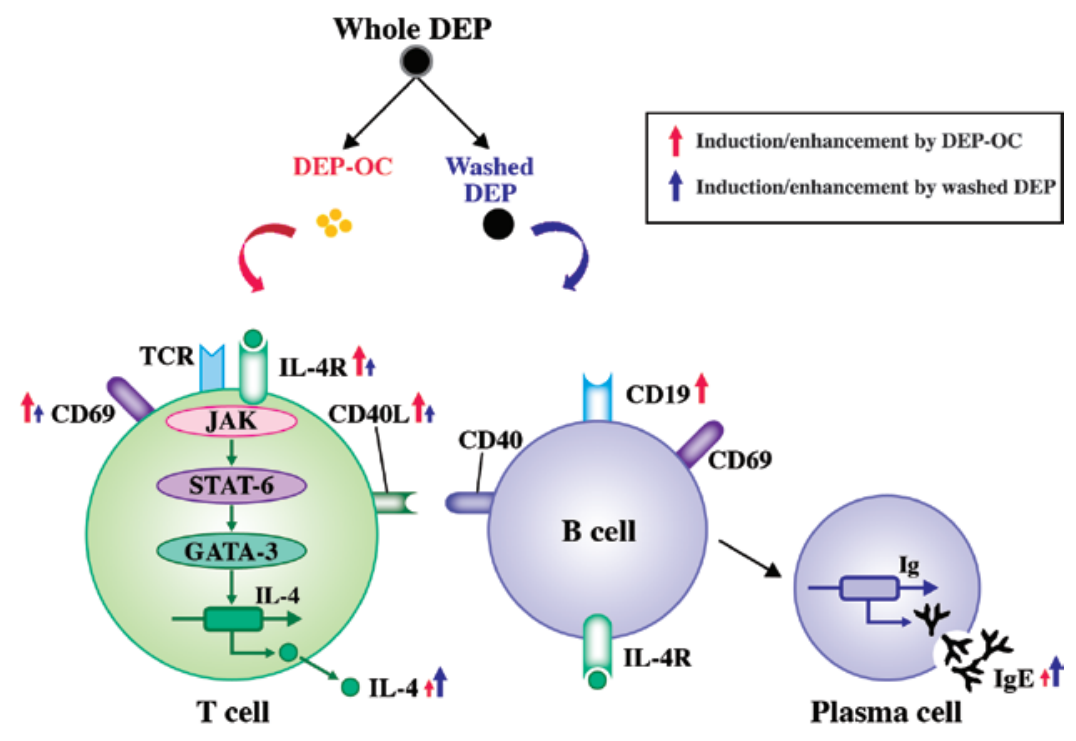

Figure 4. Possible schema of the differential effects of DEP components on DEP-mediated Th2-skewing in naïve mononuclear cells.

on the surface expression of molecules related to lymphocyte activation $24 \mathrm{~h}$ after the culture of naïve splenocytes and their $\mathrm{T}$ cells, we analyzed the expression patterns of CD19 (on splenocytes; Fig. 2), IL-4R, CD69 and CD40L (on splenocytes and T cells) by FACS (Fig. 3). Exposure to whole DEP, washed DEP or DEP-OC significantly increased CD19 expression on splenocytes as compared to the level of CD19 expression on splenocytes exposed to the control medium $(\mathrm{P}<0.01$; Fig. 2). The expression levels of IL-4R, CD69 or CD40L were significantly higher on both splenocytes and isolated $\mathrm{T}$ cells treated with whole DEP $(100 \mu \mathrm{g} / \mathrm{ml})$ or DEP-OC $(50 \mu \mathrm{g} / \mathrm{ml})$ than the expression levels on cells treated with medium alone $(\mathrm{P}<0.01)$. Also, the level was higher on cells treated with washed DEP ( $\mathrm{P}<0.01$ for IL-4R on both cells, CD69 or CD40L on splenocytes; $\mathrm{P}<0.05$ for $\mathrm{CD} 40 \mathrm{~L}$ on $\mathrm{T}$ cells) compared to the level on cells treated with medium; however, the level was lower on cells treated with DEP-OC $(\mathrm{P}<0.01$ for IL-4R on splenocytes, CD69 or CD40L; data not shown).

\section{Discussion}

The present study demonstrated that DEP exposure induces IL-4 and IgE production and several surface markers related to lymphocyte activation by mouse naïve mononuclear cells and/or isolated T cells in vitro. Studies on their constituents show that both DEP components induce IL-4 production by splenocytes and isolated $\mathrm{T}$ cells and consequent IgE synthesis in splenocytes; however, the effect is generally greater for washed DEP than for DEP-OC. In contrast, DEP-OC only increased the surface expression of CD19 on splenocytes. Furthermore, although both components increased the surface expression of IL-4R, CD69 and CD40L on both splenocytes 
and isolated T cells, the impact was significantly greater for DEP-OC than for washed DEP with an overall trend.

With respect to the adjuvant activity of DEP on atopic pathophysiology, there are two major aspects, i.e., impacts on allergens/antigens and on host immunity. DEP reportedly absorb several allergens, such as Lol p1, Bet v 1, Der p 1, Fel d 1 and Can $\mathrm{f} 1(26,27)$. Furthermore, D'Amato et al demonstrated that, by adhering to the surface of airborne allergens, such as pollen grains and/or plant-derived paucimicronic components, air pollutants including DEP, modify their antigenic properties (28), although the underlying mechanisms remain to be determined. On the other hand, DEP and/or DE were reported to directly/indirectly influence several host cell populations, particularly immune cells, leading to the progression/development/exacerbation of allergic disorders in vitro. For example, DEP and their components directly activated B cells to enhance IgE production $(29,16)$, chemical constituents of DEP induced IL-4 production/release by human-derived basophils (12) and DE exposure decreased IL-12 (Th1 cytokine) production from alveolar macrophages or a macrophage cell line (RAW264.7 cell) in vitro (30) as well as that in lung homogenates in vivo (2). Furthermore, DEP was found to suppress T-bet expression and interferon- $\gamma$ production by isolated $\mathrm{T}$ cells from healthy humans, implicating DEP in promoting Th2-skewed responses in lymphocytes $(31,32)$. In the present study, whole DEP and their components (washed DEP and DEP-OC) induced IL-4 production and IgE synthesis from splenocytes. Our present study was, accordingly, consistent with these previous studies $(31,32)$ with an overall trend; however, in the present study, we first demonstrated that DEP components differentially contributed to the adjuvant effects on allergic reaction, i.e., washed DEP and DEP-OC induced a Th2 response (IL-4 production with $\mathrm{IgE}$ de novo synthesis) in splenocytes, including $\mathrm{T}$ cells, whereas DEP-OC had a marked potential to up-regulate IL-4R (with CD69, CD40L and CD19) on these cells, which conceivably culminates in the promotion of Th2-skewed immune reactions and consequent atopic immunopathology (Fig. 4). In addition, we and another group found that DEP activated dendritic cells, professional antigen-presenting cells, to favor allergen-specific Th2 immunogenicity in vitro $(33,13)$. Thus, the present study also expanded the previous ones in that DEP and their components favor a Th2 milieu in naïve splenic mononuclear cells and $\mathrm{T}$ cells isolated from splenocytes, even in the absence of antigen-presenting cells (plus allergen), indicating that these toxicants have the potential to promote an allergic pathophysiology irrespective of allergen sensitization and/or DC/T cell interaction.

We previously demonstrated that DEP components differentially affect allergic lung inflammation in vivo, i.e., DEP-OC predominantly exacerbated allergic inflammation, whereas washed DEP did not aggravate the pathology (19). Also, in the present study, DEP-OC induced IL-4/IgE production/synthesis, implying a role in the Th2 milieu even in the absence of allergen-priming. Furthermore, DEP-OC markedly induced the surface expression of CD19, suggesting a role in $\mathrm{B}$ cell-plasma cell activation. These in vitro effects of DEP-OC support the adjuvant property against Th2-mediated pathobiology in vivo (19) and also might be one of the mechanisms explaining the phenomenon (19). Notably, however, washed DEP also significantly elevated IL-4 production with IgE synthesis in the present study. Conversely, our previous in vivo study demonstrated that pulmonary exposure to washed DEP in asthmatic mice did not increase the lung expression of Th2-type cytokines, such as IL-4, IL-5 and IL-13, but did exacerbate Th1-type cytokines, such as interferon- $\gamma$ (19). These inconsistent results may be explained by a difference between in vitro and in vivo studies. As compared to an in vivo condition (19), washed DEP easily come into contact with immune cells and stimulate/activate them in vitro. In support of this, we confirmed that carbon (black) nanoparticles, which are ultrafine particles less than $100 \mathrm{~nm}$ in mass median aerodynamic diameter compared to washed DEP (200 nm), exacerbate allergic airway inflammation even in vivo (25). Furthermore, the enhancement was greater with smaller $(14 \mathrm{~nm})$ than with larger $(56 \mathrm{~nm})$ nanoparticles (25), suggesting that more mobile particles have a higher adjuvant potential. On the contrary, a soluble component, DEP-OC, may influence systemic allergic response (broadly) likely reaching the spleen, thereby yielding profound adverse effects on allergic pathophysiology in vivo. Alternatively, DEP-derived carbonaceous compounds (washed DEP) may have antiallergic properties against alveolar macrophages and/or lung resident cells, including endothelial cells, epithelial cells and fibroblasts rather than mononuclear cells, which can hinder the enhancing effects in vivo. Further studies are required to address this issue.

CD69 is an early activation marker of hematopoietic cells. The molecule is reportedly linked to the activation of Th1 lineage in vitro (34) and Th1-dominant immunopathology in vivo (35). CD40-CD40L (CD154) interaction is crucial in the regulation of crosstalk between both dendritic (DC)-T and DC-B cells (36). In the present study, DEP-OC exposure dramatically up-regulated CD69 and CD40L on both splenocytes and $\mathrm{T}$ cells. It is attractive to speculate that the amplifying effect on CD69 expression partially contributes to relatively weaker IL-4 synthesis by DEP-OC causally via altering Th1/Th2 homeostasis than that by washed DEP. Alternatively, DEP-OC may fully show their adjuvant effects on allergic reactions in cases of (allergen)/antigen-presenting cells/lymphocytes rather than naïve (physiological) conditions/ cells. Future investigations are necessary employing the same protocol involving Th2 cells with or without allergenpriming.

There are some limitations regarding this study. We used splenocytes and isolated $\mathrm{T}$ cells from these cells, not completely matching the real situation in terms of the exposure pattern, as humans are exposed to particulate matter (PM), including DEP mainly through the airway route. However, our recent ex vivo studies showed that pulmonary exposure to DEP potentiates CD4 polarization (37) with an allergenspecific Th2 response in splenocytes of asthmatic mice (13), suggesting that these extrathoracic lymphoid cells are a target. In the future, nevertheless, the same protocol as in the present study should be employed involving draining lymph node cells around respiratory systems, such as cervical and mediastinal nodes. In any case, the present study may provide a clue for future novel screening tests to detect the pro-allergic activity of other conceivable pollutants, such as airborne PM, nanomaterials and environmental chemicals to elicit allergic reactions. Nonetheless, investigation of intracellular signaling regarding the differential effects of DEP components in depth 
to identify molecular targets is warranted. We are currently examining this using a T-cell line (Jurkat cells). In the cell line, whole DEP and washed DEP significantly and DEP-OC modestly activated ERK1/2 of MAP kinase (unpublished data) consistent with a previous report (32).

In summary, whole DEP and their components induced IL-4 production with IgE synthesis from naïve splenocytes and/or splenocyte-derived $\mathrm{T}$ cells in vitro. The effects were stronger with residual carbonaceous nuclei in DEP than with organic chemical components, whereas, organic chemical components markedly increased the surface expression of molecules related to B-cell activation, such as CD19, and T-cell activation, such as IL-4R, CD69 and CD40L, on these cells. These data indicate the pro-allergic effects of DEP on lymphoid-lineage cells, even in the absence of allergenpriming in vitro, and raise the possibility that each component in DEP differentially affects immune cells, which culminates in an increase in the DEP-mediated exacerbation of allergic inflammatory conditions with maladaptive Th2 immunity.

\section{Acknowledgements}

This study was partly funded by grants from the Grantin-Aid (\#20120014 to H. Takano) for Scientific Research on Innovative Areas. The authors thank Rie Yanagisawa, Naoko Ueki, Satomi Abe and Rieko Shibahara for the assistance throughout the study.

\section{References}

1. Ichinose T, Furuyama A and Sagai M: Biological effects of diesel exhaust particles (DEP). II. Acute toxicity of DEP introduced into lung by intratracheal instillation. Toxicology 99: 153-167, 1995.

2. Takano H, Yoshikawa T, Ichinose T, Miyabara Y, Imaoka $\mathrm{K}$ and Sagai M: Diesel exhaust particles enhance antigen-induced airway inflammation and local cytokine expression in mice. Am J Respir Crit Care Med 156: 36-42, 1997.

3. Ichinose T, Takano H, Miyabara Y and Sagai M: Long-term exposure to diesel exhaust enhances antigen-induced eosinophilic inflammation and epithelial damage in the murine airway. Toxicol Sci 44: 70-79, 1998.

4. Miyabara Y, Takano H, Ichinose T, Lim HB and Sagai M: Diesel exhaust enhances allergic airway inflammation and hyperresponsiveness in mice. Am J Respir Crit Care Med 157: 1138-1144, 1998.

5. Takano H, Ichinose T, Miyabara Y, Yoshikawa T and Sagai M: Diesel exhaust particles enhance airway responsiveness following allergen exposure in mice. Immunopharmacol Immunotoxicol 20: 329-336, 1998.

6. Terada N, Maesako K, Hiruma K, Hamano N, Houki G, Konno A, Ikeda T and Sai M: Diesel exhaust particulates enhance eosinophil adhesion to nasal epithelial cells and cause degranulation. Int Arch Allergy Immunol 114: 167-174, 1997.

7. Takizawa H, Abe S, Okazaki H, Kohyama T, Sugawara I, Saito Y, Ohtoshi T, Kawasaki S, Desaki M, Nakahara K, Yamamoto K, Matsushima K, Tanaka M, Sagai M and Kudoh S: Diesel exhaust particles upregulate eotaxin gene expression in human bronchial epithelial cells via nuclear factor-kappa B-dependent pathway. Am J Physiol Lung Cell Mol Physiol 284: L1055-L1062, 2003.

8. Terada N, Hamano N, Maesako KI, Hiruma K, Hohki G, Suzuki K, Ishikawa K and Konno A: Diesel exhaust particulates upregulate histamine receptor $\mathrm{mRNA}$ and increase histamineinduced IL-8 and GM-CSF production in nasal epithelial cells and endothelial cells. Clin Exp Allergy 29: 52-59, 1999.

9. Beck-Speier I, Dayal N, Karg E, Maier KL, Schumann G, Schulz H, Semmler M, Takenaka S, Stettmaier K, Bors W, Ghio A, Samet JM and Heyder J: Oxidative stress and lipid mediators induced in alveolar macrophages by ultrafine particles. Free Radic Biol Med 38: 1080-1092, 2005.
10. Hirota $\mathrm{R}$, Akimaru $\mathrm{K}$ and Nakamura $\mathrm{H}$ : In vitro toxicity evaluation of diesel exhaust particles on human eosinophilic cell. Toxicol In Vitro 22: 988-994, 2008.

11. Saneyoshi K, Nohara O, Imai T, Shiraishi F, Moriyama H and Fujimaki H: IL-4 and IL-6 production of bone marrow-derived mast cells is enhanced by treatment with environmental pollutants. Int Arch Allergy Immunol 114: 237-245, 1997.

12. Devouassoux G, Saxon A, Metcalfe DD, Prussin C, Colomb MG, Brambilla C and Diaz-Sanchez D: Chemical constituents of diesel exhaust particles induce IL-4 production and histamine release by human basophils. J Allergy Clin Immunol 109: 847-853, 2002.

13. Inoue $\mathrm{K}$, Koike $\mathrm{E}$, Takano $\mathrm{H}$, Yanagisawa $\mathrm{R}$, Ichinose $\mathrm{T}$ and Yoshikawa T: Effects of diesel exhaust particles on antigenpresenting cells and antigen-specific Th immunity in mice. Exp Biol Med 234: 200-209, 2009.

14. Porter M, Karp M, Killedar S, Bauer SM, Guo J, Williams D, Breysse P, Georas SN and Williams MA: Diesel-enriched particulate matter functionally activates human dendritic cells. Am J Respir Cell Mol Biol 37: 706-719, 2007.

15. Takenaka H, Zhang K, Diaz-Sanchez D, Tsien A and Saxon A: Enhanced human IgE production results from exposure to the aromatic hydrocarbons from diesel exhaust: direct effects on B-cell IgE production. J Allergy Clin Immunol 95: 103-115, 1995.

16. Tsien A, Diaz-Sanchez D, Ma J and Saxon A: The organic component of diesel exhaust particles and phenanthrene, a major polyaromatic hydrocarbon constituent, enhances IgE production by IgE-secreting EBV-transformed human B cells in vitro. Toxicol Appl Pharmacol 142: 256-263, 1997.

17. IARC: Monographs on the Evaluation of Carcinogenic Risks to Humans: Diesel and Gasoline Exhaust and Some Nitoarenes. Lyon, France, 1989.

18. Heo Y, Saxon A and Hankinson O: Effect of diesel exhaust particles and their components on the allergen-specific IgE and IgG1 response in mice. Toxicology 159: 143-158, 2001.

19. Yanagisawa $R$, Takano $H$, Inoue $K$, Ichinose $T$, Sadakane $K$, Yoshino S, Yamaki K, Yoshikawa $\mathrm{T}$ and Hayakawa $\mathrm{K}$ : Components of diesel exhaust particles differentially affect Th1/ Th2 response in a murine model of allergic airway inflammation. Clin Exp Allergy 36: 386-395, 2006.

20. Sagai M, Furuyama A and Ichinose T: Biological effects of diesel exhaust particles (DEP). III. Pathogenesis of asthma like symptoms in mice. Free Radic Biol Med 21: 199-209, 1996.

21. Takano H, Yanagisawa R, Ichinose T, Sadakane K, Yoshino S, Yoshikawa $\mathrm{T}$ and Morita M: Diesel exhaust particles enhance lung injury related to bacterial endotoxin through expression of proinflammatory cytokines, chemokines, and intercellular adhesion molecule-1. Am J Respir Crit Care Med 165: 1329-1335, 2002.

22. Yanagisawa R, Takano H, Inoue K, Ichinose T, Sadakane K, Yoshino S, Yamaki K, Kumagai Y, Uchiyama K, Yoshikawa T and Morita M: Enhancement of acute lung injury related to bacterial endotoxin by components of diesel exhaust particles. Thorax 58: 605-612, 2003.

23. Kawasaki S, Takizawa H, Takami K, Desaki M, Okazaki H, Kasama T, Kobayashi K, Yamamoto K, Nakahara K, Tanaka M, Sagai $M$ and Ohtoshi T: Benzene-extracted components are important for the major activity of diesel exhaust particles: effect on interleukin-8 gene expression in human bronchial epithelial cells. Am J Respir Cell Mol Biol 24: 419-426, 2001.

24. Julius MH, Simpson E and Herzenberg LA: A rapid method for the isolation of functional thymus-derived murine lymphocytes. Eur J Immunol 3: 645-649, 1973.

25. Inoue $K$, Takano $H$, Yanagisawa $R$, Sakurai $M$, Ichinose $T$, Sadakane $\mathrm{K}$ and Yoshikawa T: Effects of nano particles on antigen-related airway inflammation in mice. Respir Res 6: 106, 2005.

26. Knox RB, Suphioglu C, Taylor P, Desai R, Watson HC, Peng JL and Bursill LA: Major grass pollen allergen Lol p 1 binds to diesel exhaust particles: implications for asthma and air pollution. Clin Exp Allergy 27: 246-251, 1997.

27. Ormstad H, Johansen BV and Gaarder PI: Airborne house dust particles and diesel exhaust particles as allergen carriers. Clin Exp Allergy 28: 702-708, 1998.

28. D'Amato G, Liccardi G, D'Amato M and Cazzola M: Outdoor air pollution, climatic changes and allergic bronchial asthma. Eur Respir J 20: 763-776, 2002.

29. Zhang K, Clark EA and Saxon A: CD40 stimulation provides an IFN-gamma-independent and IL-4-dependent differentiation signal directly to human B cells for IgE production. J Immunol 146: 1836-1842, 1991. 
30. Saito Y, Azuma A, Kudo S, Takizawa H and Sugawara I: Effects of diesel exhaust on murine alveolar macrophages and a macrophage cell line. Exp Lung Res 28: 201-217, 2002.

31. Ohtani T, Nakagawa S, Kurosawa M, Mizuashi M, Ozawa M and Aiba S: Cellular basis of the role of diesel exhaust particles in inducing Th2-dominant response. J Immunol 174: 2412-2419, 2005.

32. Sasaki Y, Ohtani T, Ito Y, Mizuashi M, Nakagawa S, Furukawa T, Horii A and Aiba S: Molecular events in human T cells treated with diesel exhaust particles or formaldehyde that underlie their diminished interferon-gamma and interleukin-10 production. Int Arch Allergy Immunol 148: 239-250, 2009.

33. Chan RC, Wang M, Li N, Yanagawa Y, Onoe K, Lee JJ and Nel AE: Pro-oxidative diesel exhaust particle chemicals inhibit LPS-induced dendritic cell responses involved in T-helper differentiation. J Allergy Clin Immunol 118: 455-465, 2006.
34. Harimaya A, Himi T, Fujii N, Tarkkanen J, Carlson P, Ylikoski J and Mattila P: Induction of CD69 expression and Th1 cytokines release from human peripheral blood lymphocytes after in vitro stimulation with Alloiococcus otitidis and three middle ear pathogens. FEMS Immunol Med Microbiol 43: 385-392, 2005.

35. Hernandez-Garcia C, Fernandez-Gutierrez B, Morado IC, Banares AA and Jover JA: The CD69 activation pathway in rheumatoid arthritis synovial fluid T cells. Arthritis Rheum 39: 1277-1286, 1996.

36. Ma DY and Clark EA: The role of CD40 and CD154/CD40L in dendritic cells. Semin Immunol 21: 265-272, 2009.

37. Inoue $\mathrm{K}$, Koike $\mathrm{E}$, Yanagisawa $\mathrm{R}$ and Takano $\mathrm{H}$ : Effects of pulmonary exposure to diesel exhaust particles on extrathoracic CD4 polarization in asthmatic mice. Immunopharmacol Immunotoxicol 31: 71-74, 2009. 